\title{
MARKET SIMULATION IN PRESENT SCENARIO
}

\author{
Ankita Chandra
}

\begin{abstract}
Market simulation is a combination of various processes that includes developing, executing and refining marketing strategies. In the current scenario, it involves learning the essentials of internet for sales and profitability. Simulating marketing is about using marketing techniques to bring potential customers to the company, seek their attention and turn the strangers into satisfied customers and thereby turning them to promoters. It aims at creating irresistible experiences that connect with people personally and create the desire to share with others. Market simulation is an approach focused on attracting customers through contents and interactions that are relevant and helpful. It comprises inbound and outbound marketing techniques. Inbound marketing is a practice for drawing customers to products and services via content marketing, social media marketing and search engine optimization. It is about creating and sharing content with the world by creating the content specifically designed to appeal to the dreams of the customers. On the other hand, outbound marketing methods include advertisements on social media through television and mobile as well as through print media.

Index Terms: Marketing, Customization, Personalization
\end{abstract}

\section{INTRODUCTION}

This paper is based upon the exploratory as well as descriptive study. It is an exploratory study when people's perception about inbound marketing is studied to suggest new methods to improve services and customer base of brand value proposition and it is a descriptive study to analyze various techniques of marketing adopted by different companies.

In any research, sampling plays a very vital role as it provides a fair idea about the complete population without actually study each and every item of population. Marketing is the study and management of exchange relationships. The American Marketing Association explains the activity, set of institutions, and processes for creating, communicating, delivering, and exchanging offerings that have value for customers, clients, partners, and society at large." Market simulation is marketing research, a technique in which consumers is exposed to a number of advertising techniques and purchase decisions that observes their responses to a new product.

The main aim of marketing is to discover new customers and grow the business. In order to achieve this business, one will have to spend time, put sustained effort and substantial expenditure to highlight new audiences and reach out to them with various forms of marketing promoting the business or service.

Revised Manuscript Received on July 05, 2019

Ankita Chandra, Department of Management Studies, Periyar Maniammai Institute of Science \& Technology, Thanjavur, India
Inbound marketing refers to a style of marketing that is designed to bring visitors to the organization. It envisages content marketing, social media marketing and search engine optimization to seek their attention and attract the strangers into satisfied customers and subsequent promoters.

The emergence of new technology, rapidly changing customer habits and increasing demand for new ways for users reach out and effective communication with businesses has resulted in a paradigm shift from traditional outbound marketing to an inbound approach. Today's customer is savvy and has a wealth of business information at their fingertips all vying for attention and hence they have moved from the old outbound marketing techniques to the new inbound marketing techniques.

\section{MATERIALS AND METHODS}

Face to face interview method of different respondents for the purpose of qualitative analysis during the study was conducted. Based on the literature review, the questionnaire was drafted for conducting a quantitative analysis using the variables which were customized to suite the objectives of the current study. The questionnaire contains demographic profile of each consumer age group, education level, income level and occupation.

The samples were chosen randomly and methodology was convenience sampling. For exploratory research, convenient sampling procedure is used in which 40 respondents from the city are consulted. These respondents were asked to fill the prepared questionnaire on which further analysis is done and is compared with descriptive study. Data is presented with the help of bar diagram, graphs, pie charts, tables and figures.

\section{OBSERVATION AND RESULTS}

The present studies indicated the role of perceived enjoyment in online shopping. More than $60 \%$ of the respondents prefer to shop from the e- commerce sites because they find it simple and cost effective. The respondents who preferred online shopping were mainly young adults who were mostly students or had freshly started their career.

The consumers are taken by the inbound marketing systems and they have more choices available for their brand preferences for the product or services. At times, quality perception with cost perception is combined to arrive at the assessment for the value of the product. They have a good experience when the marketers ask their opinion to customize the products. Experiential marketing is effective in establishing brand imagery

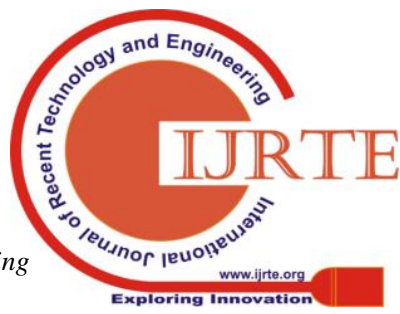


and a variety of benefits. It acts as the analyst of both group intentions and social identity which have a constructive impact on perceived advertisement relevance.

\section{DISCUSSION}

It has been found in the present study, that the young generation is more interested in shopping online because it is easy, cost effective and gives varied options to fulfill their requirements. By examining some of the items from universe (which are best representation of population), one can assume the overall behavior of population.

The term inbound marketing was first used by Halligon and Shah (2009) in their seminal book, but the concept has been around much longer. Permission marketing is the privilege of delivering anticipated, personal and relevant messages to people who actually want to get them. By specifically designing the content to appeal to the dreams of the customers, inbound attracts qualified prospects to business and keep long term relations with the customers. Since 2006, inbound marketing has been the most effective marketing method for online business.

Inbound marketing is about using marketing to bring potential customers to the products and services of the company. It aims at creating irresistible experiences that connect with people personally and create the desire to share with others. Inbound marketing is about generating and sharing content with the World.

Instead of the old outbound marketing methods that included advertisements on television, print media etc., inbound marketing focuses on creating quality content that attracts people towards the company, its products and services. It involves alignment of the contents published in the interest of the potential customers, attract inbound traffic to convert, close and delight them from time to time.

Research findings (Bleoju et al., 2016) indicated that, 54 percent of consumers find personalized advertisements to be more appealing and 74 percent of customers indicated that they desire some type of content personalization. In order to increase customer engagement, companies are now-a-days moving towards personalized marketing. The American Marketing Association states that marketing today is full of personalization. Using data-driven insights, brands craft messaging, particularly across the digital-ad stratosphere that is individualized to best reflect the interests and behaviors of their customers. Personalized marketing is a marketing strategy by which the companies customize the products or services through personal interaction between a company and its customers (Adobe). It includes controlling data analysis and digital technologies to deliver individualized messages and product offerings to current or prospective customers.

The research article by State of Inbound in 2015, suggests that mobile advertisements blocking have increased year on year by $90 \%$. Customers have more power than the marketers. Thus, the marketers need to target its customers by one-to-one marketing. As the economy shifts from products to experiences, consumers want personalized ones. The report of Harvard Business Review (2011) indicates that more than $79 \%$ of US consumers expect personalized experiences from the brands.

Personalized advertising, also known as interest-based promotions, enables advertisers to reach users, based on their interests and demographics. According to the Business Insider (2016) Google drives $95 \%$ of all paid ad clicks on mobile. Of late, companies are implementing strategies of personalization into their marketing campaigns. According to EPi Server's data, $14 \%$ of marketers indicated that personalized campaigns generate a better response rate than mass-market campaigns. The technique of customization has also been adopted by Harley Davidson, where each motorcycle is different because it can be modified according to the need of the customer. Similarly, the great innovation of Dell was to let customers personalize the specifications of their computers.

Interactive media strategies and digital tools have enabled advertisers to target the prospective customers with promotional offers and creative appeals. It was pioneered by Amazon in its retailing website under books category. Apart from motivation, personalized advertising also provides better information insights that increase the relevancy of an advertisement.

Sampling is the process of selecting units (e.g., people, organizations) from a population of interest so that by studying the sample we may fairly generalize our results back to the population from which they were chosen. The researchers typically rely on sampling in order to acquire a section of the population to perform an experiment or observational study. Bar charts have been used for the analysis of source of awareness, not using scheme and frequency of usage. The data was analyzed using SPSS 16.0.0.

The changed scenario of marketing strategies includes the use of mobile and messaging app. In digital media, programmatic advertising has exploded in recent years. Due to increasing online shopping the e-commerce companies are trying to lower their operating costs and have modified shipping and delivery processes. The increasing payment through different mobile wallets has also become popular. Group intention towards advertisements and perceived advertisement relevance have a positive impact on perceived advertisement value, which in turn has a positive response.

Finally, it is perceived that group intention towards advertisements and perceived advertisement relevance have an affirmative impact on perceived advertisement value, which in turn has a positive response. Peers have an intrinsic position in making the choice of a certain brand, product or service.

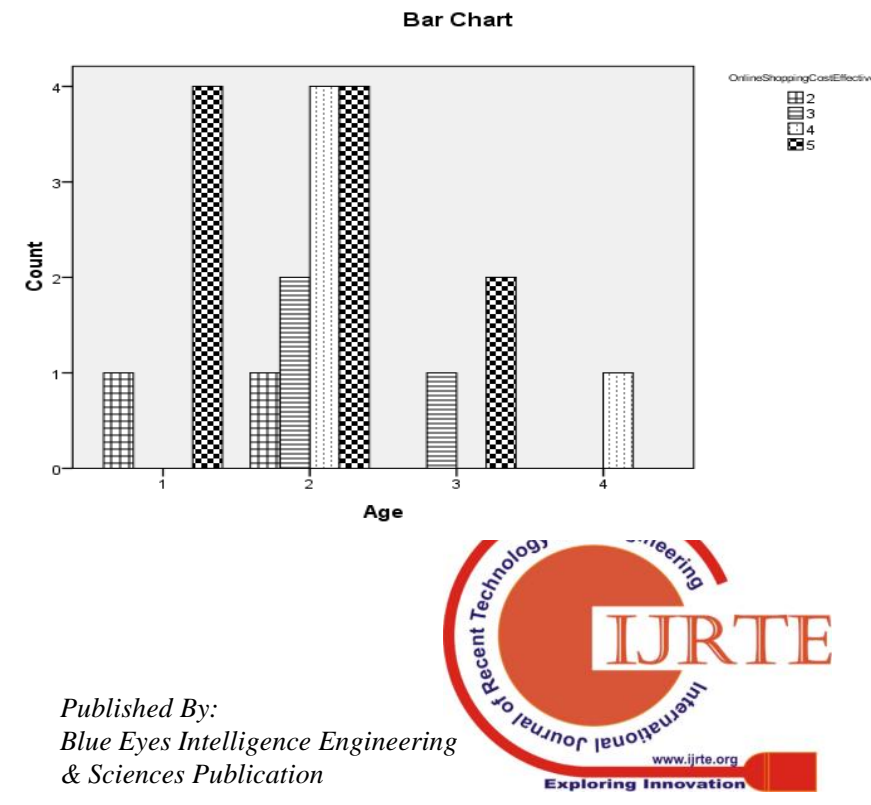


Fig 1: Age-wise online shopping behavior

The concept holds that the company should make marketing decisions by considering consumer's wants, the company's requirements and the society's long term interests. Thus it aims to achieve sustainability. In order to create more customized and personalized advertisements based on audience data, firms now moved towards social media platform.

Table I: People preferring online Inbound Shopping Methods

\begin{tabular}{|c|c|c|c|c|}
\hline & Frequency & Percent & $\begin{array}{c}\text { Valid } \\
\text { Percent }\end{array}$ & $\begin{array}{c}\text { Cumulative } \\
\text { Percent }\end{array}$ \\
\hline 1 & 5 & 25 & 25 & 25 \\
\hline 2 & 11 & 55 & 55 & 80 \\
\hline 3 & 3 & 15 & 15 & 95 \\
\hline 4 & 1 & 5 & 5 & 100 \\
\hline Total & $\mathbf{2 0}$ & $\mathbf{1 0 0}$ & $\mathbf{1 0 0}$ & \\
\hline
\end{tabular}

Bar Chart

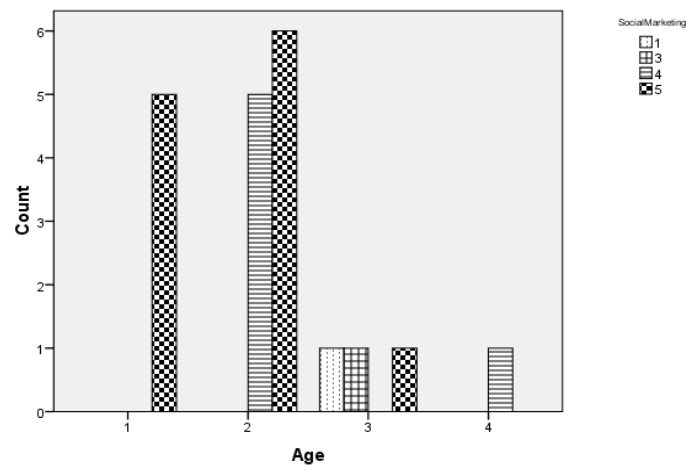

Fig 2: Age-wise social marketing

Social marketing is very popular among the youth. It is an approach that is used to develop activities aimed at changing or maintaining people's behavior for the benefit of the individual and the organization as a whole. It is the process of gaining traffic or attention through the social media.

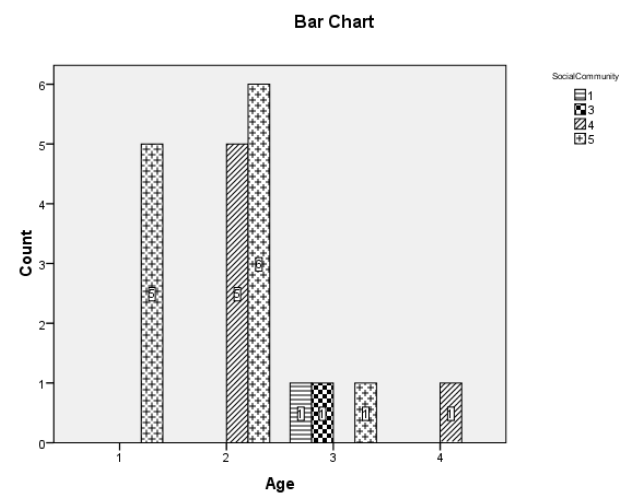

Fig 3: People having a social community
Most of the companies have also used social media to spread the message about their work and to take its advantage. These pages also feature various blogs, photos, videos, newsletters etc. about the firm. The website of the company, addresses to various questions like who they are, what they do, their achievements and resources. There is also a link directing the viewers to the Blog page. Therefore in this modern age, personalization and mass customization of advertisements are the buzz words for the success of many companies involving innumerable categories.

Bar Chart

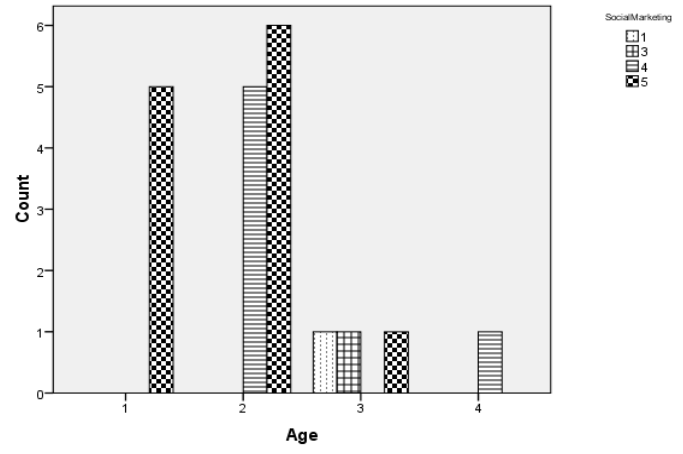

Fig 4: Consumers attracted on social websites

Personalization is a more human approach to inbound marketing. It leads to highly targeted campaigns and increases velocity and efficiency in the sales cycle. It is relevant and appealing. It attracts the lead, converts prospects and grows customer value. As a result, it helps to build a strong customer base and develop customer loyalty.

Paid search accounts for 47 per cent of online advertising budgets. The State of Inbound (2016) mentions that over 2 billion people use Facebook to search for content every day. Further, companies also create a Facebook page to connect easily with their clients and customers. Of late companies are implementing strategies of personalization into their marketing campaigns. According to EPiServer's data, 14\% of marketers are indicated that personalized campaigns generate a better response rate than mass-market campaigns.

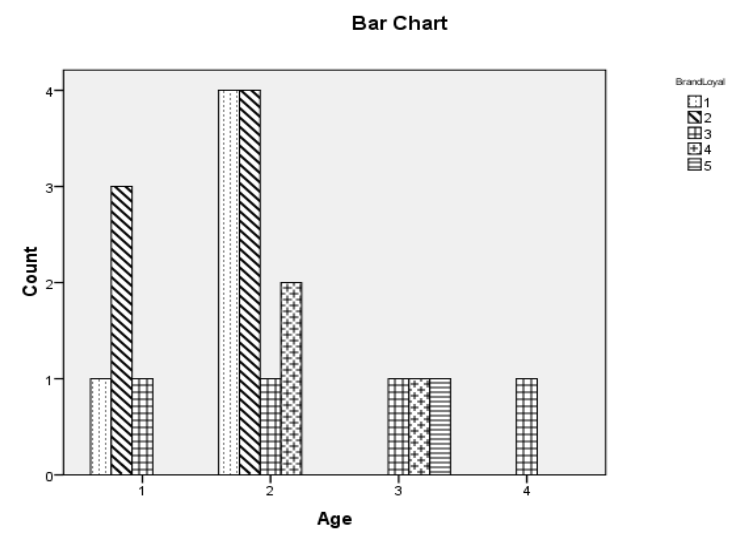

Fig 5: Customers being Brand Loyal 
As consumers have become more empowered, they have also become more difficult to please, often with misstep on the part of the brand leading to silent dissolution of their client base. It has been found out that the customers switch between the brands on the basis of price, quality, features and benefits that they derive out of the brand.

It has been found that price is a key element in keeping the loyalty of the customers. Quality is the next. More than 26\% of consumers would switch to other brands due to perceived quality issues in their products. The dissatisfied customers are keen to switch their brands if they are unhappy with the after sale service facilities or the management aspects of a certain brand.

The easiest way to start creating more personal experience about the customers can be done by sending e-mails. According to the E-consultancy report of 2016, three-quarters of companies agree that email offers 'excellent' to 'good' ROI. The mail should not be auto generated. Instead it should be sent by a member of the marketing team and should bear the recipients' name. Forrester Research (2014) has interviewed dozens of companies to learn about their experiences with personalization. In Forrester's report, "Create a Pragmatic Personalization Program", one can learn, where others have failed, and get a guide on how to succeed. It may also provide more content delivery platforms.

Many companies give a title to their trade which introduces them to the business. The title should be creative to hold the clientele. For example, the punch line of Google Shopping Campaign is "Turn online browsing into online buying." Inbound marketing is therefore required to serve in the market, as it shapes a brand preference and influence future purchases (Chandra et al., 2017). It generates social media content and inbound marketing links and also it increases brand awareness. It determines the uniqueness of the brand to target the audience to make a favorable decision for the brand. While establishing a company, the first requirement is that the company should have a catchy name and should provide the products produced as a result of superior technology, requirements and needs of the customers. It should develop marketing strategies to attract more and more customers by developing and maintain goodwill of the customers. Widespread use of digital and social media for disseminating information about the organization, products, sales and service has to play an important role.

\section{REFERENCES}

[1]Haligon, A., and Carlos Shah, J, "Advertising in online social networks: the role of perceived enjoyment and social influence", Journal of Research in Interactive Marketing, 8(3) 245-263, 2009.

[2]Harvard Business Review BR, 1103-Mag-Eng, 2011

[3] Maria Soares, A., and Carlos Pinho, J, "Advertising in online social networks: The role of perceived enjoyment and social influence", Journal of Research in Interactive Marketing 8(3) 245-263, 2014.

[4]Social Media Examiner, (Source: https://www.hubspot.com/marketing-statistics), 2015.

[5]Adobe , "Adobe Voice: Why Personalization is key to the future of marketing", Forbes, Retrieved on 05-02, 2016.

[6]Bleoju, G., Capatina, A., Rancati, E., and Lesca, N, "Exploring organizational propensity toward inbound-outbound marketing techniques adoption: The case of pure players and click and mortar companies", Journal of Business Research, 2016.
[7]Köhler,A.,and Gründer, M., "Social Media-Marketing. In Online-Marketing für die erfolgreiche Zahnarztpraxis” pp 93-118, 2016. [8]The State of Inbound, (Source: http://www.stateofinbound.com), 2016. [9]Chandra, A, "Inbound Marketing: Approach to Brand Personalization In: S.K. Shukla, A. Tripathi and AK Pandey (eds.)", Second National Conference on Emerging Trends in Computing and Management Technologies (NCETCMT), pp. 23-27, 2017.

[10] https://support.google.com/adsense. Accessed on Sep 27, 2018

[11] http://www.businessinsider.in/sai Accessed on Oct 1, 2018

[12] http://www.episerver.com/personalization/ Accessed on Oct 2, 2018.

[13] https://hbr.org/ Accessed on Oct 2, 2018

[14] https://www.forbes.com Accessed on Oct 3, 2018 